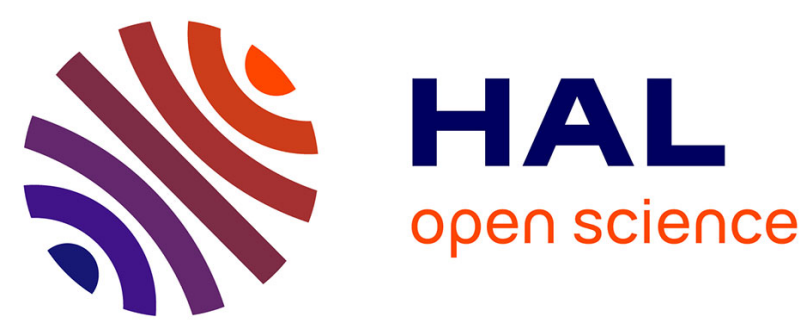

\title{
Highly Porous Hybrid Metal-Organic Nanoparticles Loaded with Gemcitabine Monophosphate: a Multimodal Approach to Improve Chemo- and Radiotherapy
}

Xue Li, Erika Porcel, Mario Menendez-miranda, Jingwen Qiu, Xiaomin Yang, Christian Serre, Alexandra Pastor, Didier Desmaele, Sandrine Lacombe, Ruxandra Gref

\section{- To cite this version:}

Xue Li, Erika Porcel, Mario Menendez-miranda, Jingwen Qiu, Xiaomin Yang, et al.. Highly Porous Hybrid Metal-Organic Nanoparticles Loaded with Gemcitabine Monophosphate: a Multimodal Approach to Improve Chemo- and Radiotherapy. ChemMedChem, 2019, 15 (3), pp.274 - 283. 10.1002/cmdc.201900596 . hal-03007090

\section{HAL Id: hal-03007090 https://hal.science/hal-03007090}

Submitted on 16 Nov 2020

HAL is a multi-disciplinary open access archive for the deposit and dissemination of scientific research documents, whether they are published or not. The documents may come from teaching and research institutions in France or abroad, or from public or private research centers.
L'archive ouverte pluridisciplinaire HAL, est destinée au dépôt et à la diffusion de documents scientifiques de niveau recherche, publiés ou non, émanant des établissements d'enseignement et de recherche français ou étrangers, des laboratoires publics ou privés. 


\section{CHEMMEDCHEM}

CHEMISTRY ENABLING DRUG DISCOVERY

\section{Accepted Article}

Title: Highly porous hybrid metal-organic nanoparticles loaded with gemcitabine-monophosphate: a multimodal approach to improve chemo and radiotherapy

Authors: Xue LI, Christian Serre, Erika Porcel, Mario MenendezMiranda, Jingwen Qiu, Xiaomin Yang, Alexandra Pastor, Didier Desmaële, Sandrine Lacombe, and Ruxandra Gref

This manuscript has been accepted after peer review and appears as an Accepted Article online prior to editing, proofing, and formal publication of the final Version of Record (VoR). This work is currently citable by using the Digital Object Identifier (DOI) given below. The VoR will be published online in Early View as soon as possible and may be different to this Accepted Article as a result of editing. Readers should obtain the VoR from the journal website shown below when it is published to ensure accuracy of information. The authors are responsible for the content of this Accepted Article.

To be cited as: ChemMedChem 10.1002/cmdc.201900596

Link to VoR: http://dx.doi.org/10.1002/cmdc.201900596 


\title{
Highly porous hybrid metal-organic nanoparticles loaded with gemcitabine-monophosphate: a multimodal approach to improve chemo and radiotherapy
}

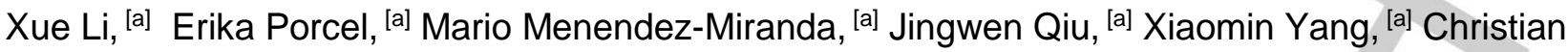 \\ Serre, ${ }^{[b]}$ Alexandra Pastor, ${ }^{[c]}$ Didier Desmaële, ${ }^{[c]}$ Sandrine Lacombe ${ }^{*}$, ${ }^{[a]}$ Ruxandra Gref ${ }^{*}{ }^{[a]}$
}

[a] Dr. X. Li (0000-0003-0254-643X), Dr. E. Porcel (0000-0001-8048-4276), Dr. M. Menendez-Miranda (0000-0002-2992-1351), J. Qiu (0000-0003-4344-
3728), X. Yang (0000-0003-0372-148X), A. Pastor, Dr. S. Lacombe (0000-0003-3334-9201), Dr. R. Gref (0000-0002-7869-0908)
Institut de Sciences Moléculaires d'Orsay,
UMR CNRS 8214, Université Paris-Sud, Université Paris-Saclay
Rue André Rivière, 91405 Orsay Cedex, France.
Emails : ruxandra.gref@u-psud.fr ; sandrine.lacombe@u-psud.fr
Dr. C. Serre (0000-0003-3040-2564)
Institut des Matériaux Poreux de Paris, FRE 2000, Ecole Normale Supérieure de Paris,
Ecole Supérieure de Physique et de Chimie Industrielles de Paris, PSL Research University
24 rue Lhomond, 75005 Paris, France
Dr. D. Desmaële (0000-0003-4013-4655)
Institut Galien,
UMR CNRS 8612, Université Paris-Sud, Université Paris-Saclay,
5 Rue Jean-Baptiste Clément, 92290 Châtenay-Malabry, France.
Supporting information for this article is given via a link at the end of the document

\begin{abstract}
Nanomedicine recently emerged as a novel strategy to improve the performance of radiotherapy. Here we report the first application of radioenhancers made of nanoscale metal-organic frameworks (nanoMOFs), loaded with Gemcitabine-monophosphate (Gem-MP), a radiosensitizing anticancer drug. Iron trimesate nanoMOFs possess a regular porous structure with oxocentered $\mathrm{Fe}$ trimers separated by around $5 \AA$ (trimesate linkers). This porosity is favorable to diffuse the electrons emitted from nanoMOFs due to activation by $g$ radiation, leading to water radiolysis and generation of hydroxyl radicals which create nanoscale damages in cancer cells. Moreover, nanoMOFs act as "Trojan horses", carrying their Gem-MP cargo inside cancer cells to interfere with DNA repair. By displaying different mechanisms of action, both nanoMOFs and incorporated Gem-MP contribute to improve radiation efficacy. The radiation enhancement factor of Gem-MP loaded nanoMOFs reaches 1.8 , one of the highest values ever reported. These results pave the way towards the design of engineered nanoparticles in which each component plays a role in cancer treatment by radiotherapy.
\end{abstract}

\section{Introduction}

Despite advances and refinements in cancer early detection and treatment, the vast majority of human malignancies are not effectively eradicated and there is a clear need to develop more efficient treatments based on combined modalities. Chemoradiation, the combination of chemotherapy and radiotherapy, is now the standard of care for many of solid tumors, including lung, esophageal, head and neck cancers. ${ }^{[1-3]}$ Advantageously, synergistic effects were reported in chemoradiation, since some anticancer drugs not only interfere with cell metabolism, but they also make cancer cells more sensitive to radiotherapy. ${ }^{[4]}$ In clinical studies, Gemcitabine (Gem) showed improved therapeutic effects in combination with irradiation even at very low dosages (less than $50 \mathrm{mg} / \mathrm{m}^{2}$ per week). ${ }^{[5]}$
Gem is a prodrug which relies on the intracellular enzyme deoxycytidine kinase to form its active intermediates: mono-, di-, and triphosphate derivatives ${ }^{[6]}$ It has been shown both in vitro and in vivo that after phosphorylation this drug exerts its cytotoxic effects and induces radiosensitization mainly through inhibition of DNA synthesis. ${ }^{[7]}$ However, the first intracellular phosphorylation of Gem is the rate-limiting step and especially difficult for resistant cancer cells. ${ }^{[6,8]}$ The administration of Gem monophosphate (Gem-MP) is hampered by its poor stability in biological media and poor cellular uptake. ${ }^{[6]}$ Moreover, because of lack of tumor targeting and specificity, healthy-tissue toxicity of this drug is the major drawback. ${ }^{[5,9]}$ In this challenging context, some of us have shown that Gem-MP could be protected against degradation with increased cellular uptake by encapsulation in nanoparticles (NPs). ${ }^{[10]}$ Nanotechnology has proven the effectiveness to target tumors, strategy of particular interest for drug delivery by achieving drug transcytosis, drug targeting and theranostics. ${ }^{[11,12]}$ In addition to the benefits of NPs for drug delivery, the potential value of metal based NPs as radioenhancers has been discovered in 2000. ${ }^{[13,14]}$ Currently, there are several types of high-Z NPs in clinical development, including Au NPs, Gd NPs, and crystalline $\mathrm{HfO}_{2}$ NPs endowed with a targeting coating. ${ }^{[15]}$ More recently, porous $\mathrm{Hf}$ based nanoscale metal organic frameworks (nanoMOF) outperformed dense $\mathrm{HfO}_{2} \mathrm{NPs}^{\left[{ }^{[16-18]}\right.}$ The combination of nanoMOFs mediated radiotherapy with checkpoint blockade has been shown as a promising strategy to broaden the application of immunotherapy.

However, there are still no examples of NPs engineered to act both as radioenhancers and nanocarriers to target anticancer drugs to the tumors. We developed here this concept using porous nanoMOF loaded with Gem-MP. Iron (III) trimesate nanoMOFs MIL-100(Fe) (MIL stands for Materials from Institut Lavoisier) were shown to be biodegradable and devoid of toxicity in vivo. ${ }^{[19-21]}$ Furthermore, they act as efficient contrast agents for Magnetic Resonance Imaging (MRI) constituting promising devices for theragnostic applications. ${ }^{[22]}$ NanoMOFs' surfaces can 
also be engineered for cancer cell targeting and for long blood circulation purposes. ${ }^{[22-26]}$ Due to their hydrophilic/hydrophobic character and high surface areas up to $1700 \mathrm{~m}^{2} / \mathrm{g},{ }^{[27]}$ iron(III) trimesate nanoMOFs were successfully loaded with unprecedented amounts (up to 20-70 wt\%) of a large variety of drugs able to penetrate within their open porous MOF structures. ${ }^{[27-29]}$ For instance, phosphorylated drugs such as Gem-MP ${ }^{[10]}, A Z T-M P^{[30]}$, and AZT-TP ${ }^{[30,31]}$ were loaded with efficiencies close to $100 \%$.

MIL-100(Fe) nanoMOFs are assembled up from $\mathrm{Fe}(\mathrm{III})$ oxocentered trimers of octahedra and trimesate linkers $(1,3,5$ benzene tricarboxylate) that self-assemble to build a 3D porous architecture delimiting large $(29 \AA)$ and small $(24 \AA)$ mesoporous cages (Figure 1A). These cages are accessible for drug adsorption in the 3D-porosity through pentagonal $(5.6 \AA)$ and hexagonal windows $(8.6 \AA)$. ${ }^{[27]}$ Iron trimesate nanoMOFs were also shown to be non-toxic and to generate in biological media reactive oxygen species (ROS). ${ }^{[29,32]}$ In summary, Gem-MP loaded nanoMOFs exhibit potentially favorable characteristics for multimodal cancer treatment: i) they efficiently load and protect Gem-MP; ii) their surface can be functionalized in a versatile manner to control the interactions with biological systems and iii) they are non-toxic, biodegradable, and potentially allow monitoring by MRI accumulation at the tumor and disease evolution (theranostics).

Here we demonstrate in vitro that nanoMOFs amplify the effect of $\gamma$-rays on tumor cells killing, and for the first time, we combine radiotherapy and chemotherapy using Gem-MP loaded nanoMOFs. As a whole, this confers to these new type of nanoagents the unique synergistic effect to enhance by a factor of 1.8 the radiotoxicity of the treatment.

\section{Results and Discussion}

\section{NanoMOFs synthesis and drug incorporation}

Several methods have been described for the synthesis of MIL-

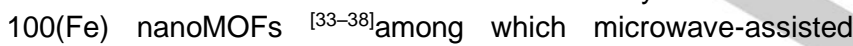
solvent-free "green" hydrothermal techniques are the most effective to obtain high yields of nanoMOFs with controlled sizes. ${ }^{[34]}$ The nanoMOFs are crystalline (Figure S1) with diffraction patterns in agreement with previous studies. ${ }^{[39,40]}$ They possessed a facetted morphology (Figure 1C) and their hydrodynamic diameters, characterized by dynamic light scattering (DLS) and NP tracking analysis (NTA), were $217 \pm 25$ $\mathrm{nm}$ and $200 \pm 64 \mathrm{~nm}$, respectively (Figure S2). NTA tracks all the individual NPs in their Brownian motion and thus gives the size distribution based on number, whereas DLS measures the fluctuations of the scattered light and is more sensitive to largest particles. A good agreement was found between the complementary DLS and NTA methods (less than 10\% differences) as previously reported with other types of NPs. ${ }^{[41]}$ NanoMOFs displayed a BET (Brunauer-Emmett-Teller) specific surface of $1740 \pm 100 \mathrm{~m}^{2} \cdot \mathrm{g}^{-1}$, in agreement with previously reported data. ${ }^{39,40]}$

Due to the strong coordination between phosphate groups and the unsaturated iron(III) Lewis acid sites from their framework, nanoMOFs acted as efficient "molecular nanosponges", soaking up Gem-MP from its aqueous solution within the large mesoporous cages $(29 \AA)$. Almost a perfect loading efficiency $(>98 \%$ ) was obtained, confirming the strong interaction between
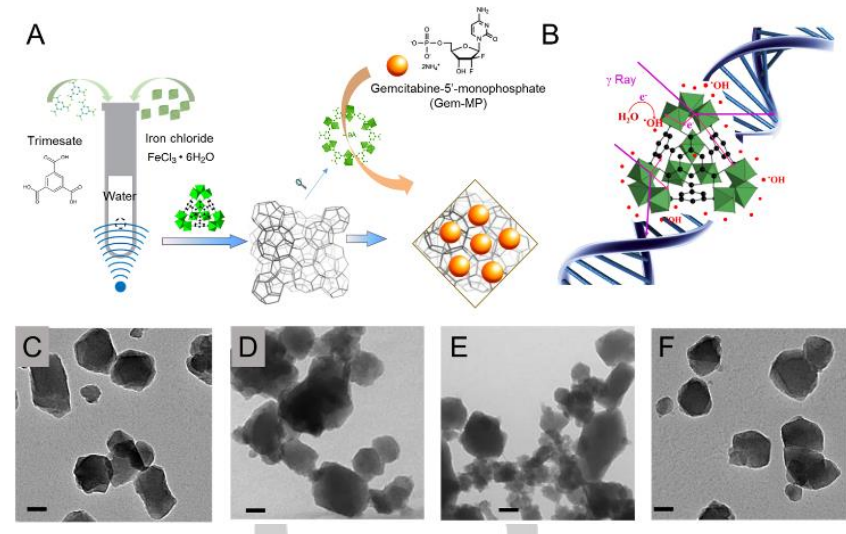

Figure 1. Schematic representation of the "green" hydrothermal synthesis of nanoMOFs and Gem-MP encapsulation (A); Fast processes ( $\mathrm{t}<10^{-12} \mathrm{~s}$ ) involved in nanoMOF excited by $\gamma$ radiations $(B)$, including the secondary electron generation and ROS production. The porous 3D structure of nanoMOF is prone to facilitate ROS diffusion. Morphology of as-synthesized nanoMOFs (C), Gem-MP loaded nanoMOF before (D) and after (E) $24 \mathrm{~h}$ incubation in water; and irradiated nanoMOFs $(F)$; scale bar in C-F: $50 \mu \mathrm{m}$.

Gem-MP and nanoMOFs due to coordination of the phosphate moiety of Gem with the $\mathrm{Fe}$ trimers which possesses two accessible unsaturated metal sites per trimer. ${ }^{[10,30]}$ Encapsulation of Gem-MP did not affect the integrity of the 3D crystalline nanoMOF structures as demonstrated by (i) morphology and size unaffected (Figure 1D) (ii) similar PXRD (Figure S1) and DLS mean diameters $(221 \pm 18 \mathrm{~nm}$ versus $217 \pm$ $25 \mathrm{~nm}$, Figure S2) as well as (iii) less than $1 \%$ release of their constitutive ligand, trimesate. NanoMOF suspensions loaded with $10 \mathrm{wt} \%$ Gem-MP were also stable in water during storage, with preserved morphology (Figure 1E) and neither detectable $(<1 \%)$ Gem-MP release nor ligand detachment $(<1 \%)$ over one day, in agreement with our previous study. ${ }^{10]}$ Gem-MP release studies were also conducted in DMEM cell culture media. Hydrodynamic diameter didn't change after $6 \mathrm{~h}$ incubation (Figure S2). As expected, nanoMOFs progressively degraded, which resulted in around $15 \%$ of Gem-MP release in the suspension media after $6 \mathrm{~h}$ incubation. This degradation is triggered by the phosphates from the media that coordinate to the iron sites leading to ligand and drug release. ${ }^{[42]}$ In our case, Gem-MP release remained lower than $20 \%$ after $24 \mathrm{~h}$ incubation in cell culture medium. (Figure S3). The efficient drug encapsulation and the stable formulation built the foundation for biological evaluation.

\section{Toxicity of nanoMOF, Gem-MP, and Gem-MP loaded nanoMOF}

These studies were completed by toxicity investigations of nanoMOFs loaded or not with Gem-MP on HeLa cells used as cellular probes. The cells were incubated with the products in the same conditions as the ones used for irradiation studies (Figure S4). As expected, free Gem-MP induced a cytotoxic effect killing $50 \%$ of cells after $6 \mathrm{~h}$ incubation at concentrations of $1.7 \mu \mathrm{g} / \mathrm{mL}$. In contrast, no significant toxicity ( $>95 \%$ cell viability) was observed with unloaded nanoMOF at concentrations of $17 \mu \mathrm{g} / \mathrm{mL}$. At equivalent concentrations, the toxicity of Gem-MP was similar whether the drug was free or incorporated in the nanoMOFs (cell viability of $53 \pm 6.4 \%$ for Gem-MP \& $52 \pm 8.1 \%$ for Gem-MP loaded 
nanoMOFs). The lack of toxicity of nanoMOFs in the irradiation conditions set up the basis for the further biological investigation.

\section{Localization and quantification of nanoMOF in HeLa cells}

Prior to irradiation experiments, the internalization of nanoMOF in HeLa cells was investigated using confocal microscopy. This tool allows detecting optical sections within cells, thus unravelling the location of the NPs. However, confocal microscopy requires labelling of the NPs with fluorescent dyes. Iron based nanoMOFs are challenging to be labelled because of dye fluorescence quenching in the pores or desorption from the surface once in contact with biological media. Figure 2A illustrates these issues: fluorescein ${ }^{[24]}$, one of the most widely employed dyes, can penetrate inside the porous $3 \mathrm{D}$ nanoMOF structure but its fluorescence was quenched. In contrast, Rhodamine (Rhod) with bulkier structure, unable to enter in the pores of the MOF, was efficiently associated to the coating of the outer surface of the nanoMOFs up to $8.2 \pm 0.2 \mathrm{wt} \%$, thus allowing a successful labelling However, around 43 wt\% of Rhod was immediately released within 5 minutes ("burst release") upon incubation in cell culture medium (Figure 2B).

In this context, to achieve an efficient Rhod labelling, stable in biological media, a new Rhod derivative functionalized with a hydrophobic anchor was synthesized. Adamantane (Ada) was chosen as lipophilic anchoring agent as its molecular size is well adapted to insert as a guest into the cages at the nanoMOFs surface, whereas the bulky hydrophilic Rhod would deploy in the suspension medium, avoiding quenching. 1-Adamantane acetic acid was successfully attached to Rhod via a short covalent linker as depicted in Figure S5. Briefly, an excess of 2,2'(ethylendioxy)bis(ethylamine) (1) was reacted with 1-adamantane acetyl chloride to give the corresponding mono amide (2), which was further acylated with succinic anhydride to provide the carboxylic acid (3). Rhod-Ada (5) was obtained by reaction with rhodamine piperazine (4) using $\mathrm{EDCl}$ as coupling agent by adapting a published procedure. ${ }^{[43]}$ The purified Rhod-Ada had similar fluorescence spectrum as Rhod, showing Excitation/Emission $=566 \mathrm{~nm} / 589 \mathrm{~nm}$ (Figure S6A).

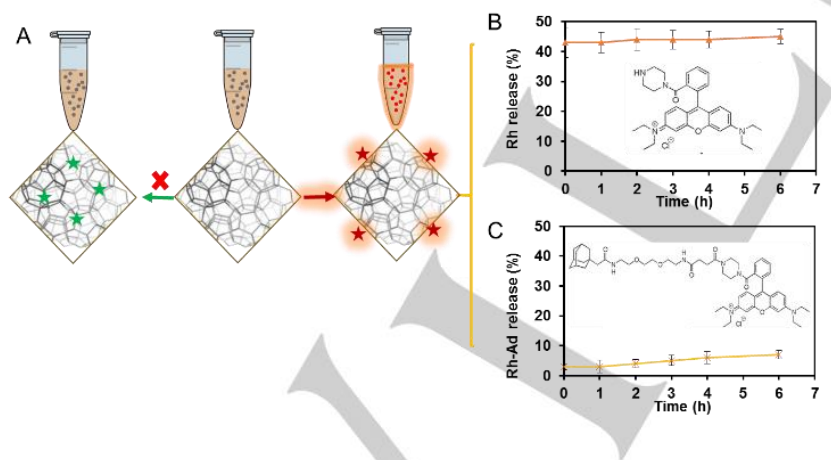

Figure 2. NanoMOF labeling with fluorescent dyes. A. Schematic representation of two strategies for nanoMOF labeling: i) fluorescent dyes which penetrate inside the porous structure of nanoMOFs, such as fluorescein, eventually quenched; ii) nanoMOFs labeled by adsorption of fluorescent dyes (Rhod, Rhod-Ada) on the surface maintain their fluorescence (red star). Rhod (B) and Rhod-Ada (C) release kinetics in cell culture medium.

Rhod-Ada was efficiently adsorbed on the surface of nanoMOFs by a simple solvent-free method, consisting in $12 \mathrm{~h}$ incubation under gentle stirring of nanoMOF aqueous suspensions containing Rhod-Ada. The amount of associated Rhod-Ada reached $7.1 \pm 0.1 \mathrm{wt} \%$ and a blue shift of 2-3 $\mathrm{nm}$ was observed for Rhod-Ada emission after adsorption on the surface of nanoMOFs (Figure S6B). In contrast with parent Rhod which detached readily from nanoMOFs (Figure 2B), Rhod-Ada showed a low release from the nanoMOFs in cell culture media, i.e. less than $10 \%$ after $6 \mathrm{~h}$ incubation (Figure 2C). As a conclusion, the newly synthesized Rhod-Ada ensures stable coatings for biological evaluations such as the study of the interactions between nanoMOFs and HeLa cells using confocal microscopy.

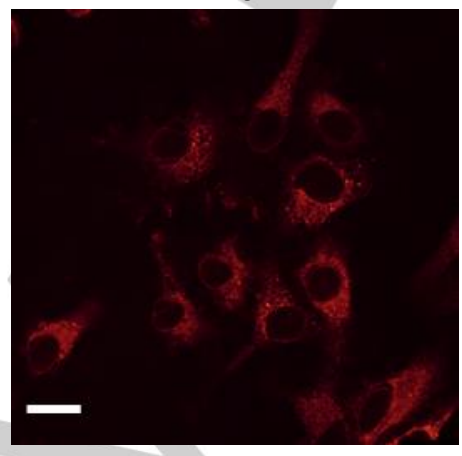

Figure 3. Confocal images of nanoMOF internalization in HeLa cells Confocal images of HeLa cells after $6 \mathrm{~h}$ incubation with Rhod-Ada labeled nanoMOFs $(100 \mu \mathrm{g} / \mathrm{mL})$ followed by intensive washing with PBS. (scale bar $25 \mu \mathrm{m})$.

As shown in Figure $\mathbf{3}$ and the video in the supporting information, the confocal images showed high intensity inside the cytoplasm, despite extensive washing to remove loosely adhered nanoMOFs. This demonstrates that nanoMOFs localized in the cytoplasm but not in the nucleus. The surface modification of nanoMOFs with Rhod-Ada could affect cellular uptake and distribution, therefore the quantification of intracellular nanoMOFs with or without Rhod Ada was performed.

The quantity of nanoMOFs internalized in the cells was determined using a procedure based on iron staining with potassium ferrocyanide. ${ }^{[25]}$ This quantification of iron content in cells was performed for concentrations ranging from 25 to 200 $\mu \mathrm{g} / \mathrm{mL}$ nanoMOFs added to HeLa cells for $6 \mathrm{~h}$ incubation. Prior to the iron dosage, the cells were washed to remove non adhered particles and then digested. As shown in Figure 4, the amount of nanoMOFs internalized in HeLa cells increased almost linearly as a function of the nanoMOF concentration. This calibration curve was used to determine the amount of internalized nanoMOFs at the concentration of $17 \mu \mathrm{g} / \mathrm{mL}$ where there was no toxicity observed. It was found that around $8 \mathrm{pg}$ nanoMOFs were associated per cell, corresponding to $1.5 \mathrm{pg} \mathrm{Fe} / \mathrm{cell}$, either internalized or firmly attached on the cell membrane.

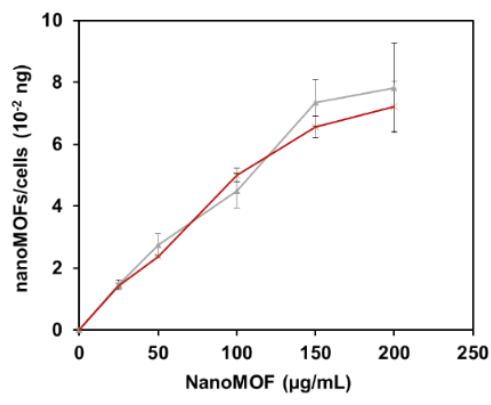


Figure 4 Quantification of nanoMOFs internalized in HeLa cells. Gray: as synthesized nanoMOFs; red: Rhod-Ada labelled nanoMOFs. NanoMOFs with different concentrations $(25,50,100,150$ and $200 \mu \mathrm{g} / \mathrm{mL})$ were incubated with $2 \times 105 \mathrm{HeLa}$ cells in 24 well plates for $6 \mathrm{~h}$, and the mass of internalized nanoMOFs was determined respectively.

\section{Impact of nanoMOFs, Gem-MP, and Gem-MP loaded nanoMOFs on radiation effects}

Prior to irradiation studies, the stability of nanoMOFs, loaded or not with Gem-MP and Gem-MP alone was investigated upon radiation using doses ranging from 4 to $6.5 \mathrm{~Gy}$.

Noteworthy, even at the highest dose, nanoMOFs kept similar facetted morphology as non-irradiated samples (Figures $1 \mathrm{~A}$ and $1 \mathrm{~F})$ with neither significant size variation after irradiation, as shown by NTA and DLS methods (Figure S2), nor degradation as indicated by the negligible loss of their constitutive ligand, trimesate $(<1 \%$, Table S1). Gem-MP was not degraded either, at the highest irradiation dose. Remarkably, nanoMOFs did not lose their Gem-MP content upon irradiation (Table S1), as indicated by negligible release of Gem-MP. These data further confirm the strong interaction between Gem-MP and nanoMOFs.

Clonogenic assay was then used to investigate the impact of nanoMOF, Gem-MP, and Gem-MP loaded nanoMOFs on cell killing induced by radiation. The colony-forming potential of cells were assessed after treatment with nanoMOFs, Gem-MP, and Gem-MP loaded nanoMOFs using a standardized procedure, where the radiation dose was fixed in the range of 1 6.5 Gy, comparable to the clinical dosage. ${ }^{[44,45]}$

Figure 5 The effect of nanoMOFs and Gem-MP on irradiation enhancement. Survival fractions of HeLa cells irradiated by $\gamma$ rays, in the presence of nanoMOF (red), Gem-MP (blue), Gem-MP loaded nanoMOF (pink), and in the control (black).

The survival curves of HeLa cells in the presence or not of GemMP, nanoMOFs and Gem-MP loaded nanoMOFs, irradiated with $\gamma$-rays, are presented in Figure 5. The cell survival fractions (SF) decreased exponentially with the increase of the radiation dose,

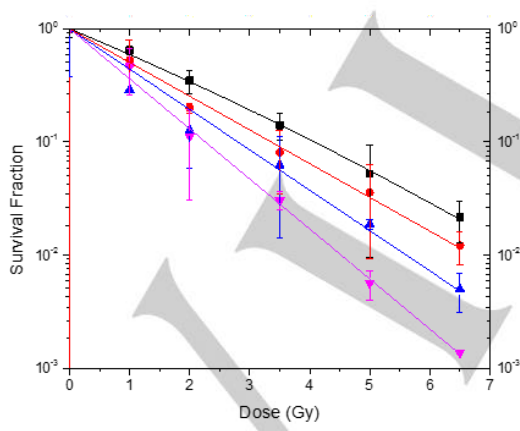

in agreement with previous reports. ${ }^{[45-48]}$ Interestingly, the bare nanoMOFs activated by $\gamma$-rays decreased significantly the cell survival. The efficiency of nanoMOFs to amplify radiation-induced cell death was evaluated by calculating the dose enhancement factor (DEF) and the radiation enhancement factor (REF) ${ }^{[15]}$ defined by the equations (1) and (2).

$\mathrm{DEF}=\mathrm{SF}_{\text {control }} / \mathrm{SF}_{\text {nanoMOFs }}$

where $\mathrm{SF}_{\text {control }}$ and $\mathrm{SF}_{\text {nanomOFs }}$ correspond to SF of the control and $\mathrm{SF}$ of treated cells at a certain dose, respectively.

$\mathrm{REF}=\mathrm{D}^{10}{ }_{\text {control }} / \mathrm{D}^{10}{ }_{\text {nanomOFs }}$ where $\mathrm{D}^{10}{ }_{\text {nanoMOFs }}$ and $\mathrm{D}^{10}$ control correspond to the radiation doses used to reach $10 \%$ of cell survival fraction in the samples treated with nanoMOFs and in the controls, respectively.

As reported in Table 1, REF value of nanoMOF alone reached 1.2. The DEF (2Gy) and DEF (4 Gy) of nanoMOF alone were found close to 1.3 and 1.5 , respectively. This is comparable to the effects observed by Mazur et al. with iron oxide NPs, showing DEF (1-4 Gy) values in the range of 1.1-1.6. ${ }^{[49,50]}$ This clearly indicates that nanoMOFs enhance radiation effects. Remarkably, the equivalent iron concentration in the nanoMOFs used in this study was much lower than the one reported in previous studies with other iron oxide NPs (nanoMOFs contain $56 \mu \mathrm{M} \mathrm{Fe}$ compared to iron oxide NPs containing $\left.3.6 \mathrm{mM} \sim 17.9 \mathrm{mM} \mathrm{Fe}^{[49,50]}\right)$. Moreover, the incubation time was also much shorter $6 \mathrm{~h}$ for nanoMOFs in comparison with $72 \mathrm{~h}$ for iron oxide NPs $\left.{ }^{[49,50]}\right)$. The amount of $\mathrm{Fe}$ internalized in cells in the case of iron oxide NPs reached up to $40 \mathrm{pg} / \mathrm{cell}$, whereas in this study, it was only 1.5 $\mathrm{pg} / \mathrm{cell}$. As a conclusion, the porous iron trimesate nanoMOFs are much more efficient to amplify radiation effects of $\gamma$-rays than solid iron oxide NPs. To the best of our knowledge, this is the first time that a radioenhancing effect of Fe-based porous material is reported.

The radioenhancement effect is due to the succession of physicochemical processes as described elsewhere for high-Z compounds and dense NPs. ${ }^{[15]}$ Of note we present here a radioenhancement effect with porous low density NPs containing iron. ${ }^{[15]}$ Briefly, the radioenhancement observed with the nanoMOFs may be explained by the activation of $\mathrm{Fe}$ atoms interacting with gamma rays, followed by de-excitation and emission of electrons. The interaction of emitted electrons with surrounding water molecules is responsible for the production of hydroxyl radicals, which are toxic for the cells. ${ }^{[15]}$ Thus, the toxicity of a radiation treatment increases with the number of electrons interacting with water molecules. Therefore it is expected that the surface area of the NPs plays an important role ${ }^{[51]}$ because the production of radicals increases with the porosity of the agent. Inversely, the number of electrons is expected to decrease when electrons do not travel to the surface, which is the case for increasing diameter of the solid particle. Advantageously, MIL$100(\mathrm{Fe})$ nanoMOFs possess a high specific BET surface area up to $1740 \mathrm{~m}^{2} \cdot \mathrm{g}^{-1}$. Moreover, their regular 3D structure with well dispersed Fe centers separated by distances of around $5 \AA$ (trimesate linkers), is favorable for a better electron traveling through the interconnected network to enhance hydroxyl radical generation and facilitate their fast diffusion in the surrounding biological medium. As a consequence, nanoMOFs act efficiently as radioenhancers despite the relatively low electron density of the emitting atoms (Fe with $\mathrm{Z}$ of 26), as compared to $\mathrm{Gd}(64), \mathrm{Au}$ (79), Pt (78) or $\mathrm{Hf}$ (72).

Table 1. Summary of REF (radiation enhancement factor), DEF(2Gy) (dose enhancement factor at $2 \mathrm{~Gy}$ ), and DEF(4Gy) obtained with HeLa cells irradiated by $\gamma$ source, in the presence of nanoMOFs, Gem-MP, Gem-MP loaded nanoMOFs. Control sample was HeLa cells treated by only $\gamma$ irradiation.

\begin{tabular}{llll}
\hline \multicolumn{1}{c}{ Sample } & REF & DEF(2Gy) & DEF(4Gy) \\
\hline control & 1 & 1 & 1 \\
nanoMOF & 1.19 & 1.30 & 1.53 \\
Gem-MP & 1.35 & 1.58 & 2.23 \\
Gem-MP loaded nanoMOF & 1.83 & 2.68 & 6.47 \\
\hline
\end{tabular}


To characterize the type of lesions amplified by nanoMOFs, SF curves were simulated using the linear quadratic law (Eq. (3) $)^{[45]}$ : $\mathrm{SF}(\mathrm{D})=\exp -\left(\alpha \mathrm{D}+\beta \mathrm{D}^{2}\right)$ where $D$ is the dose of irradiation. The coefficient $\alpha$ corresponds to the contribution of directly-lethal lesions, whereas $\beta$ is attributed to the contribution of additive sub-lethal lesions. The values of $\alpha$ and $\beta$ determined by a fitting procedure are reported in Table 2. The presence of nanoMOFs alone induces an increase in a ( 0.30 for nanoMOFs \& 0.22 for the control). This indicates an enhancement of the direct lethality of the radiation treatment in the presence of nanoMOFs.

Table 2 Calculated coefficients a and b for HeLa cells irradiated by $\gamma$ source, in the presence of nanoMOF, Gem-MP, Gem-MP loaded nanoMOF, and in the control (HeLa cells treated by only $\gamma$ irradiation). The dependency $\mathrm{R}^{2}$ values are reported in the last column.

\begin{tabular}{|c|c|c|c|}
\hline Sample & $\mathrm{a}\left(\mathrm{Gy}^{-1}\right)$ & $b\left(G y^{-2}\right)$ & $\mathrm{R}^{2}$ \\
\hline control & $0.22 \pm 0.01$ & $\begin{array}{l}0.006 \pm \\
0.002\end{array}$ & 0.9995 \\
\hline nanoMOF & $0.30 \pm 0.01$ & 0 & 0.9979 \\
\hline Gem-MP & $0.36 \pm 0.01$ & 0 & 0.9933 \\
\hline $\begin{array}{l}\text { Gem-MP } \\
\text { nanoMOF }\end{array}$ & loaded $_{0.44 \pm 0.01}$ & 0 & 0.9989 \\
\hline
\end{tabular}

The same data analysis was performed for cells treated with Gem-MP. We found that Gem-MP amplified cell death by DEF (4Gy) of 2.23 and REF of 1.35 . The increase of a (from 0.22 for the control to 0.36) shows that direct lethal damages are increased. This corresponds to the well-known effect of the drug, which agrees with former studies ${ }^{[10]}$. Thus, upon irradiation, the agent induces radiosensitization of the cells, namely an amplification of radiation effect due to perturbation of a metabolic pathway. Gem-MP is responsible for: i) induction of early $S$ phase block $^{[52]}$ via DNA inhibition at the moment of irradiation, contributing to more pronounced radiosensitizing effect; ii) inhibition of RAD51-dependent repair for DNA breaks induced by irradiation. ${ }^{[53]}$ This effect is distinct from the "radioenhancement" presented above (which is related to early stage electronic process)

For Gem-MP loaded nanoMOF, an unprecedented effect was observed. In this case, cell killing drastically increased as witnessed by the REF of 1.83 (as compared to 1.19 for nanoMOF, and 1.35 for Gem-MP alone) and by the DEF (4 Gy) up to 6.47 (as compared to 1.53 for nanoMOF and 2.23 for Gem-MP). To the best of our knowledge, the REF obtained with high-Z NPs is in the range of 1.1 to $1.6 .{ }^{[15,56]}$ Thus, the amplification effect obtained by Gem-MP loaded nanoMOF is among the highest ever reported. This is associated with a doubling of the directly lethal damage as illustrated by a increase from 0.22 (for the control) up to 0.44 , much higher than that of nanoMOFs $(0.30)$ and Gem-MP (0.36) alone. This demonstrates for the first time that the use of drug carried nanocages (Gem-MP loaded nanoMOFs) are able to combine radioenhancement and radiosensitization, which results in a much higher radio-enhancement effect superior to each element (nanoMOF and Gem-MP) considered separately. This may be explained as follows. When Gem-MP loaded nanoMOFs were incubated with HeLa cells, Gem-MP probably inhibited DNA synthesis and induced cell block in early $S$ phase, which is more sensitive to irradiation. ${ }^{[52]}$ Upon irradiation, nanoMOFs amplified the radiation effect by generating high amounts of ROS, which generated DNA damages. Gem-MP hindered reparation of DNA double-strand breaks in particular. Moreover, as previously shown, when Gem-MP loaded nanoMOFs were incubated with HeLa cells, they penetrated inside the cells, thus promoting interaction between the drug and the cells as compared with free drug unable to bypass cell membranes. This could be another reason for the improved anticancer activity after irradiation of encapsulated drug that is of high interest for clinical applications. In conclusion, radiosensitization of Gem-MP and radioenhancement of nanoMOFs complement each other to improve irradiation performance, synergistically contributing to eradicate cancer cells upon irradiation.

\section{Nanoscale impact of nanoMOFs}

To gain further insights onto the physico-chemical effects induced on biological molecules by nanoMOFs activated by radiation, we used plasmids as molecular nanoprobes to quantify the induction of nanosize (complex) damages. ${ }^{[44,54]}$ In particular, we quantified double strand breaks (DSBs), which are bigger than $2 \mathrm{~nm}$ (distance between two strands), to probe the effect of nanoMOFs on the induction of nanosize damages (Figure 1B). The addition of nanoMOFs alone (without irradiation) did not induce any damage. Upon irradiation, the number of single strand breaks (SSB) kept constant (less than $5 \%$ variation) in comparison to control, whereas DSBs increased with the dose, indicating that nanosize damages were induced. The effect of nanoMOFs on DSB is illustrated in Figure 6, where the nanoprobe was mixed with nanoMOFs and irradiated at a dose ranging from 0 up to 115 Gy. The yield of DSB, defined as the number of breaks induced per plasmid and per gray, corresponds to the slope of the dose response curves. ${ }^{[45]}$ Remarkably, when the ratio of nanoprobe over nanoMOFs was close to 200:1, the induction of DSBs was dramatically enhanced (Figure 6). In the dose range of $0 \sim 70 \mathrm{~Gy}$, DSB increased linearly with the dose, in agreement with previously reported studies with Gd-based NPs. ${ }^{[45]}$ The yield of DSB increased 2.33 times $(0.003$ for the control and 0.007 with the addition of nanoMOFs). In the dose range 70 115 Gy, DSB increased in an exponential manner (Fitting: $D S B=4 \times 10^{-5} x^{2}$. $0.0045 x+0.1831, x=$ dose). DSB was approximately 5 times higher than the control when irradiated at $115 \mathrm{~Gy}$.

These results suggest the activation of physico-chemical processes including the emission of electrons and consecutive production of water radicals, responsible for the induction of nanosize damages as explained before. In particular, the emission of electrons in water and therefore the production of reactive radicals are facilitated by the porous structure of the nanoMOFs. It thus confirms that nanoMOFs amplify the induction of nanosize damage due to physico-chemical effects and to the porous character of this agent. 


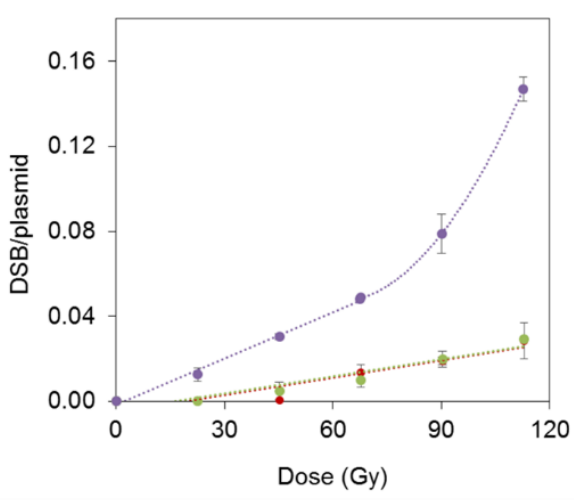

Figure 6 Yields of nanosize lesions in nanoprobes (plasmids) upon $\gamma$ rays irradiation in the presence of nanoMOFs for different plasmid:nanoMOFs ratio (red: plasmids control; green: plasmid:nanoMOFs (number ratio) $=2000: 1$; purple: plasmid:nanoMOFs (number ratio) $=200: 1$ )

\section{Conclusions}

Here we report the first proof of concept of nanoMOFs loaded with an anticancer drug to eradicate tumor cells upon irradiation. Whereas free Gem-MP is a powerful radiosensitizer, iron trimesate nanoMOFs were shown to possess intrinsic radioenhancement properties taking advantage of the ordered porous 3D structure. This approach could be extended to other drugs, provided that they are not subject to degradation upon irradiation. Non-toxic nanoMOFs acted as "Trojan horses" significantly penetrating inside cancer cells, thus promoting the cytotoxic action of entrapped Gem-MP. By displaying different mechanisms of action, both nanoMOFs activated by radiation and their Gem-MP cargo synergistically contributed to kill cancer cells. Given that nanoMOFs could act as contrast agent for MRI imaging this opens a new perspective for imaging guided chemoradiotherapy, paving the way towards a new paradigm of NPs aided radiotherapy using drug loaded radioenhancing carriers to synergistically play on different modes of action and improve cancer treatments.

\section{Experimental Section}

\section{Materials}

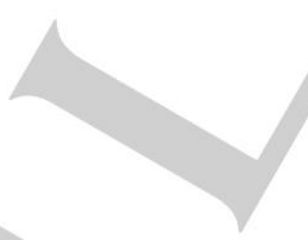

Chemical materials. Iron (III) chloride hexahydrate (98\%, Alfa Aesar, France), and 1,3,5-benzenetricarboxylic acid (trimesate, 95\%, SigmaAldrich, France) were used for the synthesis of nanoMOFs. Absolute ethanol (99\%, Carlo Erba, France) was used to purify the nanoMOFs. 2',2'difluorodeoxycytidine monophosphate (Gem-MP) was purchased from Toronto Research Chemicals (Canada). Triethylamine acetate and methanol (HPLC grade) were purchased from Sigma-Aldrich (France) as mobile phase for detection of Gem-MP.

For Rhod-Ada synthesis, diethyl ether and tetrahydrofuran (THF) were distilled from sodium/benzophenone ketyl. N,N-Dimethylformamide (DMF) and dichloromethane $\left(\mathrm{CH}_{2} \mathrm{Cl}_{2}\right)$ were distilled from calcium hydride, under nitrogen atmosphere. All reactions involving air- or water-sensitive compounds were routinely conducted in glassware which was flame-dried under a positive pressure of nitrogen or argon. 1-Adamantane acetic acid, oxalyl chloride, succinic anhydride, 1-ethyl-3-(3-dimethylaminopropyl)- carbodiimide (EDCl), hydroxybenzotriazole ( $\mathrm{HOBt})$, ethyl ether $\left(\mathrm{Et}_{2} \mathrm{O}\right)$, sodium hydroxide $(\mathrm{NaOH})$ and 2,2'-(ethylendioxy)bis(ethylamine) were obtained from Sigma-Aldrich (France). Rhodamine piperazine was obtained according to T. Nguyen et al. ${ }^{[43]}$ Chemicals obtained from commercial suppliers were used without further purification.

Cell culture. HeLa cells were grown in DMEM medium (Life Technologies, France) supplemented with $10 \% \mathrm{v} / \mathrm{v}$ decomplemented fetal bovine serum (FBS) (Life Technologies, France) at $37^{\circ} \mathrm{C}$ in humidified air containing $5 \%$ $\mathrm{CO}_{2}$.

\section{Synthesis and characterization of MIL-100(Fe) nanoMOFs}

MIL-100(Fe) nanoMOFs were synthesized as previously described by microwave assisted hydrothermal reaction. ${ }^{[34]}$ Briefly, $30 \mathrm{~mL}$ of aqueous mixture containing $6.0 \mathrm{mM}$ of iron chloride hexahydrate and $4.02 \mathrm{mM}$ of trimesic acid was heated by microwave at $130^{\circ} \mathrm{C}$ for 6 min under stirring with power of $1600 \mathrm{~W}$ (Mars-5, CEM, USA). The as-synthesized nanoMOFs were recovered by centrifugation at $10,000 \mathrm{~g}$ for $15 \mathrm{~min}$ and washed six times with absolute ethanol to remove unreacted trimesate The dynamic diameter of nanoMOFs was characterized by dynamic light scattering (DLS; Malvern Nano-ZS, Zetasizer Nano series, France). The porous surface area was measured by nitrogen sorption experiments at $196{ }^{\circ} \mathrm{C}$ on an ASAP 2020 (Micromeritics, USA) after sample degassing at $100^{\circ} \mathrm{C}$ for $15 \mathrm{~h}$ under vacuum. NanoMOFs were stored in ethanol at room temperature until further usage.

\section{Drug loading and release studies}

NanoMOFs suspensions in ethanol $(1.0 \mathrm{mg})$ were centrifuged at $10,000 \mathrm{~g}$ for $10 \mathrm{~min}$, supernatants were discarded and the pellets were re-dispersed in $1.0 \mathrm{~mL}$ of Gem-MP aqueous solution $(100 \mu \mathrm{g} / \mathrm{ml})$. After gently stirring overnight, the drug-loaded nanoMOFs were recovered by centrifugation $(10,000 \mathrm{~g}, 10 \mathrm{~min})$ and the supernatant was analyzed by HPLC to determine the amount of non-encapsulated Gem-MP. For the release studies, the Gem-MP loaded nanoMOFs $(1.0 \mathrm{mg} / \mathrm{mL})$ were centrifuged $(10,000 \mathrm{~g}, 10 \mathrm{~min})$ and redispersed in cell culture medium Dulbecco Modified Eagle Medium (DMEM) supplemented with 10\% Fetal Bovine Serum (FBS), $1 \%$ penicillin/streptomycin $(100 \mathrm{mg} / \mathrm{mL})$, and $1 \% \mathrm{~L}-$ Glutamine. Drug release studies were performed at $37^{\circ} \mathrm{C}$ with nanoMOFs concentrations of $2.5 \mathrm{mg} / \mathrm{mL}$. After different incubation times ( $30 \mathrm{~min}, 2 \mathrm{~h}$, $4 \mathrm{~h}, 6 \mathrm{~h}$, and $8 \mathrm{~h}$ ), the samples were centrifuged $(10,000 \mathrm{~g}, 10 \mathrm{~min})$. The pellets were redispersed in $10 \mathrm{mM}$ phosphate buffered saline (PBS) by vortex to totally degrade the nanoMOFs. Extracted Gem-MP was assessed by HPLC to determine the nanoMOF drug loadings.

HPLC methods. Detection of Gem-MP and TA was carried out by HPLC (Agilent 1100, USA) using a Phenomenex $\mathrm{C}_{18}$ column $(4.6 \times 250 \mathrm{~mm}, 5$ $\mu \mathrm{m})$ at a flow rate of $1.0 \mathrm{~mL} / \mathrm{min}$. A mobile phase consisting of $84 \%$ buffer (0.2 M Triethylamine Acetate): $16 \%$ methanol was used. Compounds were detected at $254 \mathrm{~nm}$ with an injection volume of $20 \mu \mathrm{l}$. Retention times of trimesate and Gem-MP were 2.67 and 3.08 min, respectively.

Stability of nanoMOF, Gem-MP, and Gem-MP loaded nanoMOF upon irradiation

NanoMOF, Gem-MP, and Gem-MP loaded nanoMOF were prepared at the concentration of $17 \mu \mathrm{g} / \mathrm{mL}, 1.7 \mu \mathrm{g} / \mathrm{mL}$, and $17 \mu \mathrm{g} / \mathrm{mL}$ for nanoMOF, Gem-MP and Gem-MP loaded nanoMOFs with 10 wt\% drug loading respectively. All the samples were incubated in water at $37^{\circ} \mathrm{C}$ for $6 \mathrm{~h}$, followed by irradiation at 4 , and 6.5 doses using a Cs-137 gamma source (energy $=0.6617 \mathrm{MeV}(\gamma)$ ) generated by GSR-D1 gamma irradiator at Institut Curie in Orsay, France. The supernatants of all samples after irradiation were recovered after centrifugation at $17,000 \mathrm{~g}$ for $20 \mathrm{~min}$ and analyzed by HPLC to quantify the amount of released TA and Gem-MP.

\section{Fluorescent labelling of nanoMOFs.}


Rhod-Ada conjugate was synthesized in order to efficiently label the nanoMOFs.

\section{General}

IR spectra were obtained as solid or neat liquid on a Fourier Transform Bruker Vector 22 spectrometer. Only significant absorptions are listed. The ${ }^{1} \mathrm{H}$ and ${ }^{13} \mathrm{C}$ NMR spectra were recorded on Bruker Avance $300(300 \mathrm{MHz}$ and $75 \mathrm{MHz}$, for ${ }^{1} \mathrm{H}$ and ${ }^{13} \mathrm{C}$, respectively) or Bruker Avance $400(400 \mathrm{MHz}$ and $100 \mathrm{MHz}$, for ${ }^{1} \mathrm{H}$ and ${ }^{13} \mathrm{C}$, respectively) spectrometers. Recognition of methyl, methylene, methine, and quaternary carbon nuclei in ${ }^{13} \mathrm{C} N M R$ spectra rests on the J-modulated spin-echo sequence. Mass spectra were recorded on a Bruker Esquire-LC. Analytical thin-layer chromatography was performed on Merck silica gel 60F254 glass precoated plates $(0.25$ $\mathrm{mm}$ layer). Column chromatography was performed on Merck silica gel 60 (230-400 mesh ASTM). These methods were used for all the following compounds.

\section{Synthesis of 2-(Adamantan-1-yl)-N-\{2-[2-(2} aminoethoxy)ethoxy]ethyl acetamide (2). To a solution of 1 adamantane acetic acid $(280 \mathrm{mg}, 1.44 \mathrm{mM})$ in $\mathrm{CH}_{2} \mathrm{Cl}_{2}(3 \mathrm{~mL})$ was added a drop of DMF and oxalyl chloride $(202 \mathrm{mg}, 1.58 \mathrm{mmol})$. The reaction mixture was stirred $2 \mathrm{~h}$ at $20{ }^{\circ} \mathrm{C}$ and then concentrated in vacuo. The residue was taken up into $\mathrm{CH}_{2} \mathrm{Cl}_{2}(10 \mathrm{~mL})$ and slowly added over three hours to 2,2'(ethylendioxy)bis(ethylamine) (2.13 g, $14.4 \mathrm{mmol}$ ) in $\mathrm{CH}_{2} \mathrm{Cl}_{2}$ $(20 \mathrm{~mL})$. The reaction mixture was stirred at room temperature for $12 \mathrm{~h}$ and concentrated under reduced pressure. The residue was treated with $0.5 \mathrm{~N}$ $\mathrm{NaOH}(10 \mathrm{~mL})$ and extracted with $\mathrm{Et}_{2} \mathrm{O}(2 \times 5 \mathrm{~mL})$. The organic layer was discarded, and the aqueous phase was extracted with $\mathrm{CH}_{2} \mathrm{Cl}_{2}(5 \times 10 \mathrm{~mL})$. The combined organic phases were dried over $\mathrm{MgSO}_{4}$ and concentrated to leave a pale yellow oil which used directly in the next step (262 mg, $56 \%)$.

IR (neat, cm ${ }^{-1}$ ) $n 3330$ (br), 2929, 2899, 2846, 1640, 1510, 1480, 1347, 1336, 1315, 1293, 1275, 1243, 1203, 1156, 1139, 1103, 1096, 989, 925, 906, 883, 725; ${ }^{1} \mathrm{H}$ NMR (300 MHz, $\left.\mathrm{CDCl}_{3}\right) \delta 6.10$ (br s, $\left.1 \mathrm{H}, \mathrm{CONH}\right), 3.58$ (s, $4 \mathrm{H}, \mathrm{OCH}_{2} \mathrm{CH}_{2} \mathrm{O}$ ), 3.55-3.45 (m, 4H, $\mathrm{CH}_{2} \mathrm{OCH}_{2} \mathrm{CH}_{2} \mathrm{OCH}$ ), 3.45-3.35 (m, $2 \mathrm{H}, \mathrm{HNCH}_{2} \mathrm{CH}_{2} \mathrm{O}$ ), 2.87 (br s, 2H), 2.19 (br s, 2H, NH ), 1.95-1.88 (m, 5H, $\left.\mathrm{CH}_{2} \mathrm{CON}, \mathrm{H}-3, \mathrm{H}-5, \mathrm{H}-7\right), 1.75-1.60$ (m, 12H, H-2, H-4, H-6, H-8, H-9, H10) ppm; ${ }^{13} \mathrm{C}$ NMR $\left(75 \mathrm{MHz}, \mathrm{CDCl}_{3}\right) \delta 171.1(\mathrm{C}, \mathrm{CON}), 73.3\left(\mathrm{CH}_{2}, \mathrm{CH}_{2} \mathrm{O}\right)$, $70.3\left(\mathrm{CH}_{2}, \mathrm{CH}_{2} \mathrm{O}\right), 70.2\left(\mathrm{CH}_{2}, \mathrm{CH}_{2} \mathrm{O}\right), 70.1\left(\mathrm{CH}_{2}, \mathrm{CH}_{2} \mathrm{O}\right), 51.7\left(\mathrm{CH}_{2}\right.$, Ada $\left.\mathrm{CH}_{2} \mathrm{CON}\right), 42.7\left(3 \mathrm{CH}_{2}, \mathrm{C}-2, \mathrm{C}-8, \mathrm{C}-9\right), 41.8\left(\mathrm{CH}_{2}, \mathrm{CH}_{2} \mathrm{~N}\right), 39.1\left(\mathrm{CH}_{2}\right.$, $\left.\mathrm{CONCH}_{2}\right), 36.9\left(3 \mathrm{CH}_{2}, \mathrm{C}-4, \mathrm{C}-6, \mathrm{C}-10\right), 32.8(\mathrm{C}, \mathrm{C}-1), 28.7(3 \mathrm{CH}, \mathrm{C}-3, \mathrm{C}-$ $5, \mathrm{C}-7) \mathrm{ppm}$; MS (ESI+): m/z (\%) = $325.3(100)\left[\mathrm{M}^{-}\right]$

\section{3-\{[2-(2-\{2-[2-(Adamantan-1 -}

yl)acetamido]ethoxy\}ethoxy)ethyl]carbamoyl\}propanoic acid (3) synthesis. A mixture of amine $2(124 \mathrm{mg}, 0.38 \mathrm{mmol})$ and succinic anhydride $(50 \mathrm{mg}, 0.51 \mathrm{mmol})$ in THF $(3 \mathrm{~mL})$ was heated at $40^{\circ} \mathrm{C}$ for 16 h. The mixture was concentrated in vaccuo and the residue was chromatographed on silica gel eluting with $\mathrm{CH}_{2} \mathrm{Cl}_{2} / \mathrm{MeOH}, 20: 1$ to leave the acid 3 as a colorless oil (113 mg, 70\%). IR (neat, $\mathrm{cm}^{-1}$ ) $n 3300$ (br), 3080 (br), 2930, 2901, 2846, 1720, 1645, 1619, 1540, 1454, 1347, 1335, $1242,1203,1173,1157,1140,1103,1095,1078,1045,990,882 ;{ }^{1} \mathrm{H}$ NMR (300 MHz, MeOH-d 4 ) $\delta 3.61$ (s, $4 \mathrm{H}, \mathrm{OCH}_{2} \mathrm{CH}_{2} \mathrm{O}$ ), 3.54 (t, $J=5.4 \mathrm{~Hz}, 4 \mathrm{H}$, $\mathrm{CH}_{2} \mathrm{OCH}_{2} \mathrm{CH}_{2} \mathrm{OCH}_{2}$ ), 3.36 (t, $\mathrm{J}=5.4 \mathrm{~Hz}, 4 \mathrm{H}, \mathrm{CONHCH}_{2} \mathrm{CH}_{2} \mathrm{O}$ ), 2.61-2.55 (m, $\left.2 \mathrm{H}, \mathrm{CH}_{2} \mathrm{CO}_{2} \mathrm{H}\right), 2.51-2.45\left(\mathrm{~m}, 2 \mathrm{H}, \mathrm{NCOCH} \mathrm{H}_{2}\right), 1.95$ (s, 5H, CH $\mathrm{CON}_{2} \mathrm{CH}$ 3, H-5, H-7), 1.80-1.60 (m, 12H, H-2, H-4, H-6, H-8, H-9, H-10) ppm; ${ }^{13} \mathrm{C}$ NMR $\left(75 \mathrm{MHz}, \mathrm{MeOH}-\mathrm{d}_{4}\right) \delta 176.0\left(\mathrm{C}, \mathrm{CO}_{2} \mathrm{H}\right), 174.5(\mathrm{C}, \mathrm{CON}), 173.8(\mathrm{C}$, $\mathrm{CON}), 71.3\left(\mathrm{CH}_{2}, \mathrm{CH}_{2} \mathrm{O}\right), 71.2\left(\mathrm{CH}_{2}, \mathrm{CH}_{2} \mathrm{O}\right), 70.6\left(\mathrm{CH}_{2}, \mathrm{CH}_{2} \mathrm{O}\right), 70.5\left(\mathrm{CH}_{2}\right.$, $\left.\mathrm{CH}_{2} \mathrm{O}\right), 51.8\left(\mathrm{CH}_{2}, \mathrm{AdaCH}{ }_{2} \mathrm{CON}\right), 43.7\left(3 \mathrm{CH}_{2}, \mathrm{C}-2, \mathrm{C}-8, \mathrm{C}-9\right), 40.3\left(\mathrm{CH}_{2}\right.$, $\left.\mathrm{CH}_{2} \mathrm{NCO}\right), 40.1\left(\mathrm{CH}_{2}, \mathrm{CONCH}_{2}\right), 37.9\left(3 \mathrm{CH}_{2}, \mathrm{C}-4, \mathrm{C}-6, \mathrm{C}-10\right)$, $33.7(\mathrm{C}, \mathrm{C}-$ 1), $31.5\left(\mathrm{CH}_{2}, \mathrm{CH}_{2} \mathrm{CH}_{2} \mathrm{CO}_{2} \mathrm{H}\right), 30.3\left(\mathrm{CH}_{2}, \mathrm{CH}_{2} \mathrm{CH}_{2} \mathrm{CO}_{2} \mathrm{H}\right), 30.17(3 \mathrm{CH}, \mathrm{C}-$ 3, C-5, C-7) ppm; MS (ESI-): m/z (\%) = 423.3 (100) [M-].

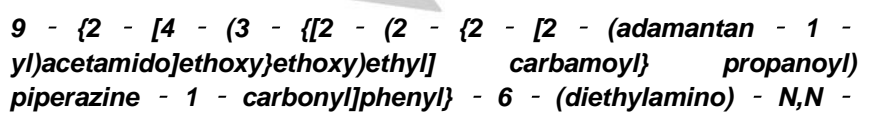

diethyl - 3H - xanthen - 3 - iminium chloride (Rhod-Ada, 5). To a mixture of rhodamine piperazine $(120 \mathrm{mg}, 0.22 \mathrm{mmol})$ and acid $3(113 \mathrm{mg}$, $0.26 \mathrm{mmol})$ in DMF $(3 \mathrm{~mL})$ was sequentially added HOBt $(10 \mathrm{mg}, 0.07$ $\mathrm{mmol}), \mathrm{EDCl}$ (56 mg, $0.29 \mathrm{mmol}$ ) and Hünig's base (148 mg, $1.15 \mathrm{mmol}$ ) The reaction mixture was stirred at $20^{\circ} \mathrm{C}$ for $24 \mathrm{~h}$ and concentrated under reduce pressure. The residue was taken up into $\mathrm{HCl} 0.1 \mathrm{~N}(5 \mathrm{~mL})$ and extracted with $\mathrm{CH}_{2} \mathrm{Cl}_{2}(3 \times 10 \mathrm{~mL})$. The combined organic phases were dried over $\mathrm{MgSO}_{4}$ and concentrated to leave a dark red oil which was chromatographed over silica gel eluting with $\mathrm{CH}_{2} \mathrm{Cl}_{2} / \mathrm{MeOH}, 20: 1$ and then $10: 1$ to give the rhodamine adamantane conjugate 5 as a dark red solid (79 mg, 47\%). ${ }^{1} \mathrm{H}$ NMR (300 MHz, $\left.\mathrm{CDCl}_{3}\right) \delta 7.90-7.67(\mathrm{~m}, 5 \mathrm{H}, 2 \mathrm{NH}, \mathrm{H}-$

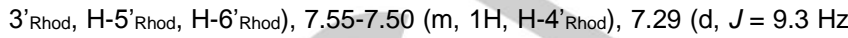
2H, H-1 Rhod, H-8Rhod), 7.07 (dd, J = 9.3 Hz, J=2.4 Hz, 2H, H-2Rhod, H-7 Rhod), 6.97 (d, $\left.1 \mathrm{H}, J=2.4 \mathrm{~Hz}, 2 \mathrm{H}, \mathrm{H}-4_{\text {Rhod, }} \mathrm{H}-5_{\text {Rhod }}\right), 3.69$ (q, J = $7.0 \mathrm{~Hz}, 8 \mathrm{H}$, $\left.\mathrm{N}\left(\mathrm{CH}_{2} \mathrm{CH}_{3}\right)_{2}\right), \quad 3.60 \quad\left(\mathrm{~s}, \quad 4 \mathrm{H}, \quad \mathrm{OCH}_{2} \mathrm{CH}_{2} \mathrm{O}\right), \quad 3.57-3.30 \quad(\mathrm{~m}, \quad 16 \mathrm{H}$, $\mathrm{CH}_{2} \mathrm{CH}_{2} \mathrm{OCH}_{2} \mathrm{CH}_{2} \mathrm{OCH}_{2} \mathrm{CH}_{2}$, $\left.\mathrm{CON}\left(\mathrm{CH}_{2} \mathrm{CH}_{2}\right)_{2} \mathrm{NCO}\right), 2.65-2.55(\mathrm{~m}, 2 \mathrm{H}$, $\mathrm{CH}_{2} \mathrm{CON}$ ), 2.50-2.42 (m, 2H, CH $\mathrm{C}_{2} \mathrm{CON}$ ), 2.00-1.90 (m, 5H, $\mathrm{CH}_{2} \mathrm{CON}, \mathrm{H}-$ $3_{\text {Ada }}, \mathrm{H}-5_{\text {Ada }}, \mathrm{H}-7_{\text {Ada }}$ ), 1.80-1.60 (m, 12H, H-2 Ada, H-4 Ada, H-6 Ada, H-8 ${ }_{\text {Ada }}, \mathrm{H}-$ $\left.9_{\text {Ada }}, \mathrm{H}-10_{\text {Ada }}\right), 1.31$ (t, $\left.J=7.0 \mathrm{~Hz}, 12 \mathrm{H}, \mathrm{N}\left(\mathrm{CH}_{2} \mathrm{CH}_{3}\right)_{2}\right) \mathrm{ppm} ;{ }^{13} \mathrm{C} \mathrm{NMR}(75$ $\mathrm{MHz}, \mathrm{CDCl}_{3}$ ) $\delta 174.7$ (C, CO), 173.9 (C, CO), 172.7 (C, CO), 169.6 (C CORhod), 159.3 (2C, C-3rhod, C-6rhod), 157.2 (2C, C-4arhod, C-4brhod),

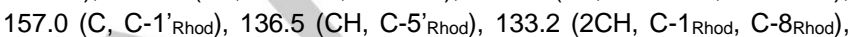

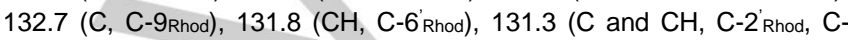

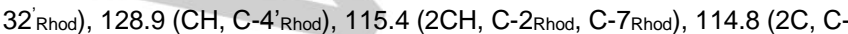

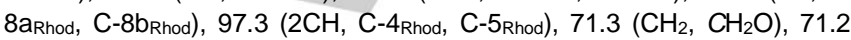
$\left(\mathrm{CH}_{2}, \quad \mathrm{CH}_{2} \mathrm{O}\right), 70.7\left(\mathrm{CH}_{2}, \mathrm{CH}_{2} \mathrm{O}\right), 70.6\left(\mathrm{CH}_{2}, \mathrm{CH}_{2} \mathrm{O}\right), 51.8\left(\mathrm{CH}_{2}\right.$, $\mathrm{AdaCH} \mathrm{CON}_{2} \mathrm{CON}, 46.9\left(4 \mathrm{CH}_{2}, \mathrm{~N}\left(\mathrm{CH}_{2} \mathrm{CH}_{3}\right)_{2}\right), 43.7\left(3 \mathrm{CH}_{2}, \mathrm{C}-2\right.$ Ada, $\mathrm{C}-8$ Ada, C9Ada), 43.2-42.6 (m, $\left.4 \mathrm{CH}_{2}, \mathrm{~N}\left(\mathrm{CH}_{2} \mathrm{CH}_{2}\right)_{2} \mathrm{~N}\right), 40.3\left(\mathrm{CH}_{2}, \mathrm{CH}_{2} \mathrm{NCO}\right), 40.1\left(\mathrm{CH}_{2}\right.$, $\left.\mathrm{CONCH}_{2}\right), 37.9\left(3 \mathrm{CH}_{2}, \mathrm{C}-4_{\text {Ada }}, \mathrm{C}-6\right.$ Ada, $\left.\mathrm{C}-10_{\text {Ada }}\right), 33.8$ (C, C-1 $\left.1_{\text {Ada }}\right), 31.5$ $\left(\mathrm{CH}_{2}, \mathrm{NCOCH}_{2} \mathrm{CH}_{2} \mathrm{CON}\right), 30.2\left(3 \mathrm{CH}, \mathrm{C}-3\right.$ Ada, $\left.\mathrm{C}-5_{\text {Ada }}, \mathrm{C}-7_{\text {Ada }}\right), 29.0\left(\mathrm{CH}_{2}\right.$ $\left.\mathrm{NCOCH}_{2} \mathrm{CH}_{2} \mathrm{CON}\right), 12.8\left(4 \mathrm{CH}_{3}, \mathrm{~N}\left(\mathrm{CH}_{2} \mathrm{CH}_{3}\right)_{2}\right) \mathrm{ppm} ; \mathrm{MS}(\mathrm{ESI}+): \mathrm{m} / \mathrm{z}(\%)=$ $917.6(100)[\mathrm{M}-\mathrm{Cl}]^{+}, 553.3(15), 539.3(14), 470(80)[\mathrm{M}-\mathrm{Cl}+\mathrm{Na}]^{2+}$

\section{NanoMOFs labeling with Rhod-Ada}

Rhod-Ada was dissolved in water at a concentration of $1 \mathrm{mM}$ and incubated overnight with nanoMOFs at a weight ratio of 1:10 (Rhod-Ad: nanoMOFs). Rhod-Ad labelled nanoMOFs were washed with water until no free RhodAd was found in the washing solution (concentration $<0.05 \mu \mathrm{g} / \mathrm{mL}$ ). Because of quenching effect of nanoMOFs, Rhod adsorption on the surface of nanoMOFs could not be directly quantified. Indirect methods were applied consisting in quantifying the initial Rhod amount added to nanoMOFs and the free Rhod in the supernatants after extensive washings of the nanoMOFs using a fluorescence spectrophotometer (VARIAN, Cary Eclipse). Rhod-Ad adsorption was calculated as the weight ratio (\%) between the adsorbed Rhod-Ad and the nanoMOFs. Rhod-Ad release was measured in cell culture medium. After incubation at $37^{\circ} \mathrm{C}$ for $1,2,4$, and $6 \mathrm{~h}$, the samples were collected by centrifugation and the detached Rhod-Ad was measured using a fluorimeter. Rhod labelling was performed in the same way as control samples.

Visualization by confocal microscopy. $3.0 \times 10^{4} \mathrm{HeLa}$ cells were seed on sterile glass slides. After incubating overnight for the cells to get attached, nanoMOFs labelled with Rhod or Rhod-Ad were incubated with living cells for $6 \mathrm{~h}$. After washing three times with PBS to remove free nanoMOFs, living cells were visualized using a LEICA SP5 confocal system, equipped with a thermostatically controlled and $\mathrm{CO}_{2}$ regulated chamber (University Paris Sud, France). Rhod and Rhod-Ad were excited at $514 \mathrm{~nm}$ and the emission from 560-600 nm were collected. The images were processed with the Image $\mathrm{J}$ software.

Fe quantification was performed by adjusting a previous reported iron staining protocol. ${ }^{[25]}$ Briefly, $2.0 \times 10^{5}$ cells were plated in 24 wells plates and incubated for $24 \mathrm{~h}$ for cell adherence. Then the cells were incubated for $6 \mathrm{~h}$ with $1 \mathrm{~mL}$ of DMEM $10 \%$ FBS or $1 \mathrm{~mL}$ of culture media containing nanoMOFs labelled or not with Rhod-Ad (nanoMOF concentration $=0 \sim 200$ $\mu \mathrm{g} / \mathrm{mL}$ ). Cells were prepared in four wells for each condition. At the end of the incubation, the cells were washed three times with PBS to eliminate 
non interacting MOFs. Cells were detached using trypsin and then counted with Luna counting (LUNA ${ }^{\mathrm{TM}}$, Logos Biosystem, Korea). Cells in four other wells cultured in the same conditions were digested with $100 \mu \mathrm{L} \mathrm{HCl}(5 \mathrm{M})$ at $60^{\circ} \mathrm{C}$ for $2 \mathrm{~h}$. At the end of the incubation, $100 \mu \mathrm{L}$ of $4 \%$ potassium ferrocyanide was added in each well. The plates were further incubated at room temperature in the dark for $30 \mathrm{~min}$. The absorbance of the treated samples was measured at $690 \mathrm{~nm}$. Calibration curves were obtained with nanoMOFs suspensions with known concentrations (0 250 $\mu \mathrm{g} / \mathrm{mL})$. The internalized nanoMOFs was quantified using HeLa cells without nanoMOFs as control.

\section{Effect of Gem-MP and nanoMOFs on SF of HeLa cells upon irradiation}

HeLa cells were cultured using DMEM media supplemented with $10 \%$ FBS $1 \%$ penicillin/streptomycin $(100 \mathrm{mg} / \mathrm{mL})$, and $1 \%$ L-Glutamine. Cells were maintained at $37{ }^{\circ} \mathrm{C}$ in a $5 \% \mathrm{CO}_{2}$ incubator. Growing cells at a density of $2 \times 10^{5}$ were seeded in flasks $\left(25 \mathrm{~cm}^{3}\right) 12 \mathrm{~h}$ before irradiation. NanoMOFs loaded or not with Gem-MP were added to the cell culture medium at an equivalent Fe concentration of $56 \mu \mathrm{M}$. After $6 \mathrm{~h}$ incubation, the compounds (nanoMOFs, Gem-MP, and Gem-MP loaded nanoMOFs) were removed and the cells were irradiated using the same Cs-137 gamma source as for the stability investigation. The cells were irradiated at ambient conditions with doses of $1,2,3.5,5$, and 6.5 Gy. The effect of radiation, nanoMOFs and Gem-MP on cells was quantified by clonogenic assay. Briefly, cells were detached with trypsin $(0.05 \%)$ and plated onto Petri dishes $(60 \mathrm{~mm})$ at a density of 100 surviving cells/dish. The plating efficiency was close to $39 \%$ for HeLa cells, whatever they interacted or not with nanoMOFs. When Gem-MP was used, the plating efficiency was close to $28 \%$. After 2 weeks of incubation, the formed cell colonies were washed twice with PBS and stained with $5 \%$ methylene blue in methanol. The colonies were finally counted to determine the surviving fractions.

Effect of Gem-MP and nanoMOFs on DNA damage induced by irradiation

Plasmids. The commercial pBR322 ( $p$ stands for "plasmid," and BR for "Bolivar" and "Rodriguez") DNA (Molecular biology, France) composed of 4361 base pairs and diluted in Tris-EDTA buffer $(0.5 \mu \mathrm{g} / \mathrm{mL})$ was used. NanoMOFs were considered as spheres with diameter of $200 \mathrm{~nm}$ and the weight of the single NP were theoretically calculated. The effect of nanoMOFs was investigated using a DNA:nanoMOFs number ratio ranging from 2000:1 to 200:1. Plasmids were irradiated with $\gamma$ source from Co-60 (energy $=1.25 \mathrm{MeV}(\gamma)$, dose rate $=4.51 \mathrm{~Gy} / \mathrm{min}$ ) in Orsay, France. After irradiation at the dose range of $0-115 \mathrm{~Gy}$, agarose gel electrophoresis was performed to analyze the samples. Briefly, the three conformers of the plasmid were separated by migration in agarose gel (1.0 wt\%) under electrophoresis at an electric intensity of $80 \mathrm{~mA}$ for $3 \mathrm{~h}$. After quantification of the three band intensities ( $S, R$, and $L$ ) by Image $J$, the respective yields of SSB and DSB were determined as previously reported. ${ }^{[55]}$ Given the fact that the $S$ forms bind 1.47 -times less ethidium bromide than $R$ and $L$ conformations, which was calculated based on the binding constant of $R$, $S$, and $L$ to ethidium bromide ${ }^{[56]}$, the fraction of $R\left(R^{\prime}\right), S\left(S^{\prime}\right)$, and $L\left(L^{\prime}\right)$ was calculated as following:

Total $=1.47 \times \mathrm{S}+\mathrm{R}+\mathrm{L}$

$\mathrm{R}^{\prime}=\mathrm{R} /$ Total

$\mathrm{S}^{\prime}=1.47 \times \mathrm{S} /$ Total

$\mathrm{L}^{\prime}=\mathrm{L} / \mathrm{Total}$

The induction of SSBs and DSBs per plasmid was determined using Poisson law statistics ${ }^{[55]}$, which is based on the discrete probability distribution that expresses the probability of a given number of events occurring in a fixed space:

SSB yield (breaks per plasmid) $=\ln \left[\left(1-L^{\prime}\right) / S^{\prime}\right]$

DSB yield (breaks per plasmid $)=L^{\prime} /\left(1-L^{\prime}\right)$

\section{Acknowledgements}

We acknowledge support from the Université Paris Saclay for the "Inititative de Recherche Stratégique" IRS NanoTheRad project. This research was funded by European Research Council through Cyclon Hit project (People-2013-ITN Grant Agreement 608407), by the French National Research Agency (ANR) grant ANR-14-CE08-0017 and the ARGENT project, Grant Agreement 608163 . This work is supported by a public grant overseen by the French ANR as part of the "Investissements d'Avenir" program (Labex NanoSaclay, reference: ANR-10-LABX-0035). We acknowledge help from Ludivine Houel Renault, responsible of the platform CPBM/CLUPS/LUMAT FR2764 for cell culture and confocal microscopy.

Keywords: metal organic frameworks - nanoparticles • radioenhancer $\cdot$ radiosensitization $\cdot$ synergistic effect

\section{References:}

[1] B. Pauwels, A. E. C. Korst, F. Lardon, J. B. Vermorken, Oncologist 2005 $10,34$.

[2] T. Song, M. Fang, S. Wu, Clin. Interv. Aging. 2018, 13, 2275

[3] F. Lim, R. Glynne-Jones, Cancer Treat. Rev. 2011, 37, 520.

[4] R. Roy, A. Maraveyas, Oncologist 2010, 15, 259.

[5] O. M. Vanderveken, P. Szturz, P. Specenier, M. C. Merlano, M. Benasso, D. Van Gestel, K. Wouters, C. Van Laer, D. Van den Weyngaert, M. Peeters, et al., Oncologist 2016, 21, 59.

[6] D. Y. Bouffard, J. Laliberté, R. L. Momparler, Biochem. Pharmacol. 1993, 45, 1857.

[7] C. H. Hsu, Mol. Pharmacol. 2004, 67, 806

[8] A. M. Bergman, H. M. Pinedo, G. J. Peters, Drug Resist. Updat. 2002, 5 , 19.

[9] A. M. Allen, M. M. Zalupski, J. M. Robertson, F. E. Eckhauser, D. Simone D. Brown, G. Hejna, D. Normolle, T. S. Lawrence, C. J. McGinn, Int. J. Radiat. Oncol. Biol. Phys. 2004, 59, 1461.

[10] V. Rodriguez-Ruiz, A. Maksimenko, R. Anand, S. Monti, V. Agostoni, P. Couvreur, M. Lampropoulou, K. Yannakopoulou, R. Gref, J. Drug Target. 2015, 23, 759

[11] D. Rosenblum, N. Joshi, W. Tao, J. M. Karp, D. Peer, Nat. Commun 2018, 9, 1.

[12] S. Senapati, A. K. Mahanta, S. Kumar, P. Maiti, Signal Transduct. Target Ther. 2018, 3, 7

[13] D. Kwatra, A. Venugopal, S. Anant, Transl. Cancer Res. 2013, 2, 330

[14] D. M. Herold, I. J. Das, C. C. Stobbe, R. V Iyer, J. D. Chapman, Int. J. Radiat. Biol. 2000, 76, 1357

[15] Z. Kuncic, S. Lacombe, Phys. Med. Biol. 2018, 63, 1.

[16] K. Lu, C. He, N. Guo, C. Chan, K. Ni, G. Lan, H. Tang, C. Pelizzari, Y. X Fu, M. T. Spiotto, et al., Nat. Biomed. Eng. 2018, 2, 600.

[17] K. Ni, G. Lan, C. Chan, B. Quigley, K. Lu, T. Aung, N. Guo, P. La Riviere R. R. Weichselbaum, W. Lin, Nat. Commun. 2018, 9, 1.

[18] K. Ni, G. Lan, S. S. Veroneau, X. Duan, Y. Song, W. Lin, Nat. Commun 2018, 9, 1.

[19] T. Baati, L. Njim, F. Neffati, A. Kerkeni, M. Bouttemi, R. Gref, M. F. Najjar A. Zakhama, P. Couvreur, C. Serre, et al., Chem. Sci. 2013, 4, 1597.

[20] T. Simon-Yarza, T. Baati, F. Neffati, L. Njim, P. Couvreur, C. Serre, R Gref, M. F. Najjar, A. Zakhama, P. Horcajada, Int. J. Pharm. 2016, 511, 1042

[21] T. Simon-Yarza, M. Giménez-Marqués, R. Mrimi, A. Mielcarek, R. Gref P. Horcajada, C. Serre, P. Couvreur, Angew. Chemie Int. Ed. 2017, 56 15565.

[22] P. Horcajada, T. Chalati, C. Serre, B. Gillet, C. Sebrie, T. Baati, J. F. Eubank, D. Heurtaux, P. Clayette, C. Kreuz, et al., Nat. Mater. 2010, 9 172.

[23] M. Giménez-marqués, E. Bellido, T. Berthelot, T. Simón-yarza, T. Hidalgo, R. Simón-vázquez, Á. González-Fernández, J. Avila, M. C Asensio, R. Gref, et al., Small 2018, 14, 1801900. 
[24] T. Hidalgo, M. Giménez-Marqués, E. Bellido, J. Avila, M. C. Asensio, F. Salles, M. V. Lozano, M. Guillevic, R. Simón-Vázquez, A. González Fernández, et al., Sci. Rep. 2017, 7, 1.

[25] S. Wuttke, S. Braig, T. Preiß, A. Zimpel, J. Sicklinger, C. Bellomo, J. O. Rädler, A. M. Vollmar, T. Bein, Chem. Commun. 2015, 51, 15752.

[26] V. Agostoni, P. Horcajada, M. Noiray, M. Malanga, A. Aykaç, L. Jicsinszky, A. Vargas-Berenguel, N. Semiramoth, S. Daoud-Mahammed, V. Nicolas, et al., Sci. Rep. 2015, 5, 7925.

[27] E. Bellido, T. Hidalgo, M. V. Lozano, M. Guillevic, R. Simón-Vázquez, M. J. Santander-Ortega, Á. González-Fernández, C. Serre, M. J. Alonso, P. Horcajada, Adv. Healthc. Mater. 2015, 4, 1246.

[28] G. Férey, C. Mellot-Draznieks, C. Serre, F. Millange, J. Dutour, S. Surblé, I. Margiolaki, Science 2005, 309, 2040.

[29] P. Horcajada, R. Gref, T. Baati, P. K. Allan, G. Maurin, P. Couvreur, Chem. Rev. 2012, 112, 1232.

[30] X. Li, N. Semiramoth, S. Hall, V. Tafani, J. Josse, F. Laurent, G. Salzano, D. Foulkes, P. Brodin, L. Majlessi, et al., Part. Part. Syst. Charact. 2019, $36,1$.

[31] V. Agostoni, R. Anand, S. Monti, S. Hall, G. Maurin, P. Horcajada, C. Serre, K. Bouchemal, R. Gref, J. Mater. Chem. B 2013, 1, 4231.

[32] V. Agostoni, T. Chalati, P. Horcajada, H. Willaime, R. Anand, N. Semiramoth, T. Baati, S. Hall, G. Maurin, H. Chacun, et al., Adv. Healthc. Mater. 2013, 2, 1630.

[33] R. Grall, T. Hidalgo, J. Delic, A. Garcia-marquez, S. Chevillard, P. Horcajada, J. Mater. Chem. B 2015, 3, 8279.

[34] M. N. Martin, A. J. Allen, R. I. Maccuspie, V. A. Hackley, Langmuir 2014 30, 11442 .

[35] V. Agostoni, P. Horcajada, V. Rodriguez-Ruiz, H. Willaime, P. Couvreur, C. Serre, R. Gref, Green Mater. 2013, 1, 209.

[36] F. Jeremias, S. K. Henninger, C. Janiak, Dalt. Trans. 2016, 45, 8637.

[37] Y. Xu, L. Xu, S. Qi, Y. Dong, Z. U. Rahman, H. Chen, X. Chen, Anal. Chem. 2013, 85, 11369.

[38] F. Zhang, J. Shi, Y. Jin, Y. Fu, Y. Zhong, W. Zhu, Chem. Eng. J. 2015, 259, 183.

[39] I. Levy, I. Sher, E. Corem-Salkmon, O. Ziv-Polat, A. Meir, A. J. Treves, A. Nagler, O. Kalter-Leibovici, S. Margel, Y. Rotenstreich, J. Nanobiotechnology 2015, 13, 34.

[40] S. R. Miller, D. Heurtaux, T. Baati, P. Horcajada, J.-M. Grenèche, C. Serre, Chem. Commun. 2010, 46, 4526.

[41] X. Li, G. Salzano, J. Zhang, R. Gref, J. Pharm. Sci. 2017, 106, 395.

[42] X. Li, L. Lachmanski, S. Safi, S. Sene, C. Serre, J. M. Grenèche, J. Zhang, R. Gref, Sci. Rep. 2017, 7, 1.

[43] T. Nguyen, M. B. Francis, Org. Lett. 2003, 5, 3245.

[44] E. Porcel, S. Liehn, H. Remita, N. Usami, K. Kobayashi, Y. Furusawa, C. Le Sech, S. Lacombe, Nanotechnology 2010, 21, 1.

[45] E. Porcel, O. Tillement, F. Lux, P. Mowat, N. Usami, K. Kobayashi, Y. Furusawa, C. Le Sech, S. Li, S. Lacombe, Nanomedicine Nanotechnology, Biol. Med. 2014, 10, 1601.

[46] M. Guo, Y. Sun, X.-D. Zhang, Appl. Sci. 2017, 7, 232.

[47] S. Shrestha, L. N. Cooper, O. A. Andreev, Y. K. Reshetnyak, M. P. Antosh, Jacobs J. Radiat. Oncol. 2016, 3, 26.

[48] A. S. Wozny, M. T. Aloy, G. Alphonse, N. Magné, M. Janier, O. Tillement, F. Lux, M. Beuve, C. Rodriguez-Lafrasse, Nanomedicine:NBM. 2017 13, 2655.

[49] C. M. Mazur, R. R. Strawbridge, E. S. Thompson, A. A. Petryk, D. J. Gladstone, P. J. Hoopes, Prog. Biomed. Opt. Imaging - Proc. SPIE 2015 9326, 1.

[50] C. M. Mazur, J. A. Tate, R. R. Strawbridge, D. J. Gladstone, P. J. Hoopes, Proc SPIE Int Soc Opt Eng. 2013, 26, 1.

[51] P. Retif, S. Pinel, M. Toussaint, C. Frochot, R. Chouikrat, T. Bastogne, M. Barberi-Heyob, Theranostics 2015, 5, 1030.

[52] B. Pauwels, A. E. C. Korst, G. G. O. Pattyn, H. A. J. Lambrechts, D. R Van Bockstaele, K. Vermeulen, M. Lenjou, C. M. J. De Pooter, J. B. Vermorken, F. Lardon, Int. J. Radiat. Oncol. Biol. Phys. 2003, 57, 1075.

[53] S. Kobashigawa, K. Morikawa, H. Mori, G. Kashino, Anticancer Res. 2015, 35, 2731.

[54] C. Le Sech, H. Frohlich, C. Saint-Marc, M. Charlier, Radiat. Res. 2006, $145,632$.
[55] M. Spotheim-Maurizot, M. Charlier, R. Sabattier, Int. J. Radiat. Biol. 1990 57, 301.

[56] Y. A. Hiroyuki Tomita, Michiaki Kai, Tomoko Kusama, J. Radiat. RES 1995, 36, 46 .

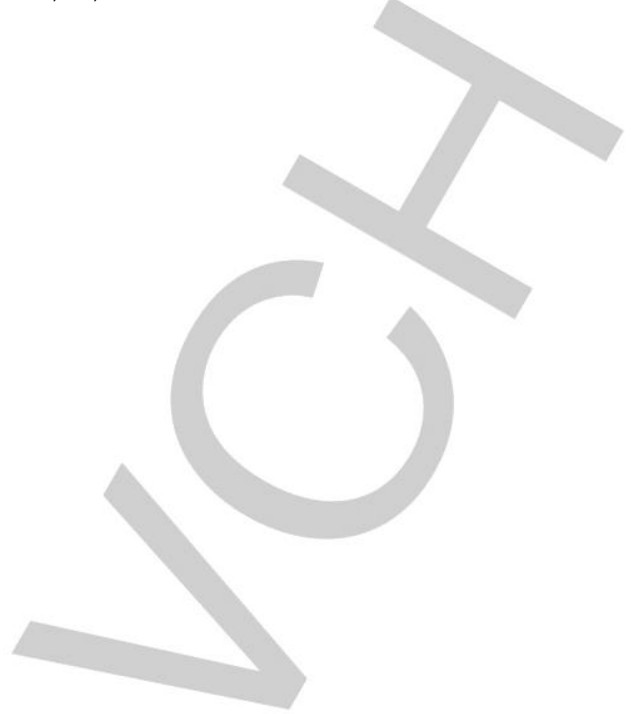




\section{Entry for the Table of Contents}

Insert graphic for Table of Contents here.

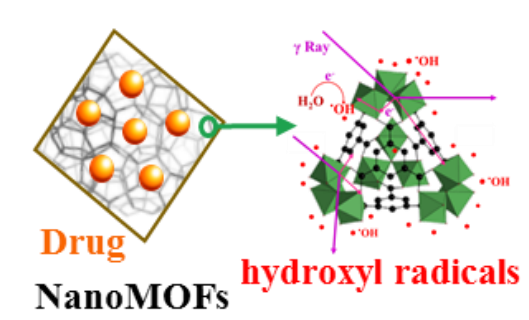

Gemcitabine-monophosphate (Gem-MP), a radiosensitizing anticancer drug, was successfully loaded in iron trimesate nanoMOFs, which possess a porous structure with oxocentered Fe trimers separated by trimesate linkers. The radiation enhancement factor of Gem-MP loaded nanoMOFs reaches 1.8 , one of the highest values ever reported. 